\title{
Elementos para uma política de desenvolvimento rural com base na agricultura familiar - a inserção do PRONAF no
}

\section{Delimitando uma política de desenvolvimento rural com base na agricultura familiar}

Para caracterizar os elementos necessários para uma política voltada ao desenvolvimento rural, deve-se considerar a grande diversidade ambiental, sócio-econômica e cultural existente no meio rural brasileiro, associada a profundas desigualdades regionais. Coexistem nesse espaço grupos sociais muito distintos, desde empresários do agribusiness até grupos tradicionais (ribeirinhos, extrativistas e comunidades indígenas), passando por fazendeiros tradicionais e por agricultores de pequeno porte com maior ou menor inserção comercial. Isso implica na possibilidade — ou antes, na necessidade — de formulação, dentro desse tema, de políticas também diferenciadas, com estratégias, objetivos e públicos bastante distintos.

Em função disso, optou-se por abordar aqui a problemática do desenvolvimento rural tendo como foco o segmento chamado de "agricultura familiar". Esse setor é caracterizado por relações sociais de produção distintas daquelas verificadas na "agricultura empresarial ou patronal", tendo por base os seguintes aspectos gerais: a) gestão da unidade produtiva por indivíduos que mantêm entre si laços de sangue ou de casamento; b) maior parte do trabalho igualmente fornecida pelos membros da família; e c) propriedade dos meios de produção (embora nem sempre da terra) pertencente à família em cujo interior se realiza a transmissão em caso de falecimento ou de aposentadoria dos responsáveis pela unidade produtiva (Guanzirolli e Cardin, 1999). Vale destacar que enquadram-se nesses critérios grupos sociais bastante distintos, não só quanto à renda, tecnologia

Especialistas em Políticas Públicas e

Gestão

Governamental.

Contato:

aloisiolpmelo@ uol.com.br 
e inserção no mercado, mas também quanto às características sócio-

culturais: assentados, arrendatários, posseiros, extrativistas, ribeirinhos, indígenas, remanescentes de quilombos, artesãos etc.

A caracterização assumida acima implica uma abordagem de desenvolvimento rural que enfatiza, mais do que aspectos produtivos, tecnológicos ou comerciais, questões como o combate à pobreza, a geração de emprego e renda, a segurança alimentar e o desenvolvimento local e sustentável. Estas questões estão associadas aos papéis que o setor desempenha (ou que se pretende que venha a desempenhar) no processo de desenvolvimento do país.

\section{Primeira seleção de programas do}

\section{PPA 2000-2003: abordagem multissetorial}

A partir da perspectiva apresentada, uma política de desenvolvimento rural deve abranger as especificidades da produção, ocupação e renda desse segmento; a problemática ambiental associada a essas atividades; as questões específicas relacionadas às condições de produção e trabalho (acesso à terra e à infra-estrutura produtiva); e ainda questões gerais relacionadas às condições de vida da população rural (ou seja, ações de educação, saúde, cultura, lazer, assistência, previdência social etc.). Este último grupo de questões é particularmente relevante em função da existência de "bolsões de pobreza rural" e de maiores dificuldades de acesso (ou menor alcance) dos serviços sociais básicos no meio rural.

Segundo essas definições, buscou-se identificar os programas do PPA 2000-2003 que seriam necessários para compor uma política voltada ao desenvolvimento rural com foco na agricultura familiar. Identificou-se, em um primeiro momento, 25 programas que, no conjunto, viabilizariam as mudanças pretendidas:

1. Agricultura Familiar;

2. Apoio ao Desenvolvimento do Setor Agropecuário;

3. Atenção à Criança;

4. Brasil Patrimônio Cultural;

5. Cesta de Alimentos;

6. Conservação de Solos na Agricultura;

7. Emancipação de Assentamentos Rurais;

8. Energia nas Pequenas Comunidades;

9. Erradicação do Trabalho Escravizador e Degradante;

10. Erradicação do Trabalho Infantil;

11. Gerenciamento da Estrutura Fundiária;

12. Gestão da Política Agropecuária;

13. Gestão da Política Fundiária;

14. Irrigação e Drenagem;

15. Luz no Campo; 
16. Municipalização do Turismo;

17. Novo Mundo Rural: Assentamentos dos Trabalhadores Rurais;

18. Novo Mundo Rural: Consolidação de Assentamentos;

19. Prevenção e Combate a Desmatamentos, Queimadas e Incêndios Florestais;

20. Produção e Abastecimento Alimentar;

21. Qualificação Profissional do Trabalhador;

22. Saneamento Básico;

23. Seguro Rural;

24. Toda Criança na Escola; e

25. Zoneamento Ecológico-econômico.

Não foram incluídos nessa seleção os programas referentes à melhoria tecnológica dos produtos agropecuários, bem como aqueles referentes às cadeias produtivas e ao agribusiness. Considerou-se que estes referem-se a uma política de desenvolvimento rural voltada especificamente à promoção comercial e em larga escala da agropecuária brasileira nos mercados interno e externo.

\section{Segunda seleção de programas do PPA 2000-2003: foco setorial}

A lista de programas apresentada representa um leque muito amplo de ações, referentes a várias políticas setoriais, além da própria política agrícola e fundiária: educação, saúde, assistência social, meio ambiente, emprego/renda, segurança alimentar, cultura, turismo e direito humanos. Dada a complexidade de se analisar detidamente cada um desses programas, optou-se, para os fins deste trabalho, por considerar que estas políticas setoriais contemplam com a mesma efetividade tanto o ambiente urbano quanto o rural, mais especificamente o segmento da agricultura familiar. Da mesma forma, optou-se por considerar que os programas voltados à produtividade e à inserção comercial do setor agropecuário estão também plenamente disponíveis (ou acessíveis) ao público em questão.

Embora sejam necessários tais pressupostos para a análise aqui apresentada, deve-se alertar que, na prática, é pouco provável que eles se verifiquem - o que reforça nossa constatação de que, na falta de inovações na sistemática de planejamento e gestão ora existentes, o pleno acesso da população rural a esse conjunto de bens e serviços somente seria garantido mediante o desenho de ações e instrumentos específicos.

Merece destaque, na abordagem de desenvolvimento rural proposta, o primeiro programa da lista, voltado especificamente para a agricultura familiar. Trata-se do Programa Nacional de Fortalecimento da Agricultura Familiar (PRONAF), que se originou da percepção (compartilhada por técnicos governamentais e organizações sociais) de que o setor deveria 
receber um tratamento específico e diferenciado, dentro do conjunto da política agrícola e das demais ações afins.

O PRONAF surgiu justamente de insatisfações quanto à falta de foco das políticas e ações preexistentes, de forma que seu desenho buscou, como veremos adiante, articular sob uma mesma unidade de gestão um amplo conjunto de ações, envolvendo diferentes órgãos e esferas de governo. Consideradas necessárias para promover o segmento da agricultura familiar, as ações previstas no PRONAF (vide Anexo II) referem-se à infra-estrutura e serviços no meio rural, crédito rural (geral e específico para a produção orgânica e para agroindústrias de pequeno porte), capacitação, assistência técnica e extensão rural, apoio ao cooperativismo e associativismo, pesquisa agropecuária e avaliação do programa.

O governo federal, ao criar o PRONAF, optou por replicar ações já existentes, focalizando-as, entretanto, no setor da agricultura familiar. Podese inferir a partir daí que o programa pretendeu constituir-se, ele próprio, em uma política de desenvolvimento rural. A despeito do caráter abrangente do PRONAF, constata-se que a política proposta não se esgota nesse programa, requerendo outras ações e instrumentos específicos, para além dos ali previstos. Uma política de desenvolvimento rural com base na agricultura familiar deveria conter, pelo menos, os seguintes elementos: a) o ordenamento do uso da terra e da estrutura fundiária; b) a garantia de acesso à terra e à infra-estrutura produtiva e social; c) a recuperação, conservação e manejo dos recursos naturais, em especial o solo e a água; d) a garantia de preços e renda e/ou o seguro contra frustrações de safra; e

e) a articulação da produção com os sistemas de abastecimento alimentar da população urbana. Neste sentido, identificou-se no PPA 2000-2003 o seguinte conjunto de programas que contempla, a princípio, esses elementos:

1. Zoneamento Ecológico-econômico;

2. Gerenciamento da Estrutura Fundiária;

3. Gestão da Política Fundiária;

4. Novo Mundo Rural: Assentamento de Trabalhadores Rurais;

5. Novo Mundo Rural: Consolidação de Assentamentos;

6. Emancipação de Assentamentos Rurais;

7. Produção e Abastecimento Alimentar;

8. Conservação de Solos na Agricultura;

9. Seguro Rural;

10. Irrigação e Drenagem;

11. Luz no Campo; e

12. Saneamento Básico.

A primeira análise a ser feita é identificar se existe articulação e complementaridade entre o PRONAF e os demais programas selecio nados. Em seguida, é necessário avaliar, segundo critérios de pertinência e 
suficiência, se o PRONAF, em conjunto com os demais programas, caracterizam uma efetiva política de desenvolvimento rural com base na agricultura familiar.

\section{Descrição da lógica identificada}

\section{Orientações estratégicas, macroobjetivos e agendas do PPA 2000-2003}

O PRONAF e os demais programas relacionados ao desenvolvimento rural com base na agricultura familiar atendem a duas orientações estratégicas do PPA 2000-2003:

- promover o desenvolvimento sustentável voltado para a geração de empregos e oportunidades de renda; e

- combater a pobreza e promover a cidadania e a inclusão social.

O PRONAF e os demais programas selecionados estão inseridos no Macroobjetivo 20: "Promover o desenvolvimento integrado do campo", especialmente no que se refere às estratégias de:

- viabilizar o agronegócio familiar mediante o desenvolvimento local integrado; e

- apoiar a pequena agroindústria com treinamento, qualificação e incentivo à sua inserção na cadeia produtiva para ampliar a competitividade da agricultura familiar no agronegócio.

No que se refere às Agendas do PPA 2000-2003, entende-se que, no desenvolvimento desse conjunto de programas, todas as Agendas deverão ser observadas subsidiariamente aos seus objetivos.

\section{Legislação}

O apoio à agricultura familiar, entendida como a pequena propriedade rural e a pequena produção, encontra respaldo, no âmbito da Constituição Federal (CF), no artigo 5o, inciso XXVI:

“(...) a pequena propriedade rural, assim definida em lei, desde que trabalhada pela família, não será objeto de penhora para pagamento de débitos decorrentes de sua atividade produtiva, dispondo a lei sobre os meios de financiar o seu desenvolvimento."

Os componentes da política agrícola são explicitados no artigo 187 da CF:

"A política agrícola será planejada e executada na forma da lei, com a participação efetiva do setor de produção, envolvendo produtores e trabalhadores rurais, bem como dos setores de 
comercialização, de armazenamento e de transportes, levando em conta, especialmente:

I - os instrumentos creditícios e fiscais;

II — os preços compatíveis com os custos de produção e a garantia de comercialização;

III — o incentivo à pesquisa e à tecnologia;

IV — a assistência técnica e extensão rural;

$\mathrm{V}$ - o seguro agrícola;

VI - o cooperativismo;

VII - a eletrificação rural e irrigação;

VIII - a habitação para o trabalhador rural."

No âmbito da lei if 8.171, de 17/01/91, conhecida como Lei Agrícola, que dispõe sobre a política agrícola, cabe destacar em seu art. 2o-, inciso VI, que:

"O processo de desenvolvimento agrícola deve proporcionar ao homem do campo acesso aos serviços essenciais: saúde, educação, segurança pública, transporte, eletrificação, comunicação, habitação, saneamento, lazer e outros bens físico-sociais."

Além disso, a referida lei relaciona, em seu artigo 47, os investimentos em forma de:

“(...) obras que o poder público deverá implantar que tenham como objetivo o bem-estar social de comunidades rurais, compreendendo, entre outras: a) barragens, açudes, perfuração de poços, diques e comportas para projetos de irrigação, retificação de cursos d'água e drenagens de áreas alagadiças; b) armazéns comunitários; c) mercados de produtor; d) estradas; e) escolas e postos de saúde rurais; f) energia; g) comunicação; h) saneamento básico; i) lazer."

Essas ações do Poder Público, previstas em lei, respaldam a expectativa do PRONAF de receber apoio complementar dos programas setoriais do PPA que contribuam para os macroobjetivos selecionados e para as orientações estratégicas a ele dirigidas.

A mesma lei, no artigo $3^{\circ}$, inciso IV, explicita como objetivos da política agrícola "proteger o meio ambiente, garantir o seu uso racional e estimular a recuperação dos recursos naturais"; no VII, "compatibilizar as ações da política agrícola com as de Reforma Agrária, assegurando aos beneficiários o apoio à sua integração ao sistema produtivo"; e no X, "prestar apoio institucional ao produtor rural, com prioridade de atendimento ao pequeno produtor e sua família."

Ela também se preocupou em integrar as ações de política agrícola, como mostra o artigo 8 -,$\S 4$ : 
“Os planos deverão prever a integração das atividades de produção e de transformação do setor agrícola, e deste com os demais setores da economia ", e o art.10, que rezam o Poder Público deverá:

I - proporcionar a integração dos instrumentos de planejamento agrícola com os demais setores da economia."

A Lei Agrícola prevê tratamento diferenciado ao pequeno produtor ao afirmar no artigo 12, inciso III, que a pesquisa agrícola deverá "dar prioridade à geração e à adaptação de tecnologias agrícolas destinadas ao desenvolvimento dos pequenos agricultores, enfatizando os alimentos básicos, equipamentos e implementos agrícolas voltados para esse público". No artigo 17, assegura que "o Poder Público manterá serviço oficial de assistência técnica e extensão rural, sem paralelismo na área governamental ou privada, de caráter educativo, garantindo atendimento gratuito aos pequenos produtores e suas formas associativas (...)". Finalmente, no artigo 52, a lei afirma que "o Poder Público assegurará crédito rural especial e diferenciado aos produtores rurais assentados em área de reforma agrária ."

Respaldado na Lei Agrícola, o PRONAF foi instituído pelo decreto no 1946, de 28 de junho de 1996, apresentando uma concepção pertinente ao desenvolvimento rural e da pequena agricultura, conforme o artigo 1o do decreto:

"Fica criado o Programa Nacional de Fortalecimento da Agricultura Familiar (PRONAF), com a finalidade de promover o desenvolvimento sustentável do segmento rural constituído pelos agricultores familiares, de modo a propiciar-lhes o aumento da capacidade produtiva, a geração de empregos e a melhoria de renda."

Outra importante característica presente na criação do PRONAF e condizente com a Agenda dos Eixos Nacionais de Integração e Desenvolvimento refere-se à ênfase na parceria entre as três esferas de governo e com a iniciativa privada, conforme explicitado no artigo 2 do decreto: "O PRONAF assenta-se na estratégia da parceria entre os Governos Municipais, Estaduais e Federal, a iniciativa privada e os agricultores familiares e suas organizações."

\section{Análise da política quanto à sua pertinência}

\section{Análise da pertinência dos programas setoriais selecionados (vide Anexo 1 - Matriz lógica dos programas)}

A partir do arcabouço legal apresentado anteriormente, busca-se aqui verificar em que medida a seleção setorial de programas do PPA 2000-2003 (item 3.3) é pertinente à política de desenvolvimento rural com 
base na agricultura familiar, conforme anteriormente delimitado. A análise de pertinência realizada não se pautou em informações referentes à implantação das ações, atendo-se somente às informações programáticas constantes do referido plano. Buscou-se na avaliação mensurar a capacidade de consecução dos objetivos de desenvolvimento a partir da pertinência das ações previstas, considerando as possibilidades de integração e complementaridade destes programas com vistas aos objetivos mais gerais da política de desenvolvimento rural, especialmente na agricultura familiar (vide Anexo I - Matriz lógica dos programas). Vale lembrar ainda que se considerou que outras políticas setoriais, de caráter universal, darão conta de elementos essenciais referentes àquela (saúde, educação, renda mínima etc.). A análise da pertinência das ações do PRONAF, carrochefe da referida política, é apresentada no próximo item.

O Programa de Zoneamento Ecológico-econômico (MMA, MI/ Sudene, Estados) contém ações de mapeamento de aptidões que são, a princípio, necessárias para subsidiar e orientar a política em questão. Por outro lado, essas informações permitem também orientar a utilização sustentável dos recursos naturais de forma a maximizar a produção, a produtividade e a renda das atividades agropecuária e extrativa — subsidiando, por exemplo, ações de crédito e seguro rural, quer pelo PRONAF, quer por programas voltados à agricultura patronal. Um limite desse programa reside no seu caráter localizado, contendo ações referentes a regiões específicas. Ainda assim, deverão ser disponibilizadas informações relevantes para a política.

As informações fornecidas pelo programa anterior deverão ser complementadas por outras, referentes à distribuição da posse da terra $\mathrm{e}$ à sua utilização, a serem levantadas pelo Programa de Gerenciamento da Estrutura Fundiária (MDA/Incra). Identifica-se aqui semelhante limite: com base nas definições contidas no PPA sobre esse programa, suas informações restringem-se às médias e grandes propriedades, e, mantido o caráter declaratório que tem, tornam muito restrito o seu alcance. Apesar do limite, as informações permitem a formulação de diretrizes de ordenamento e reordenamento fundiário, conferindo maior eficácia e efetividade às ações voltadas ao atendimento da demanda por terra e pela infra-estrutura produtiva.

A persistência das desigualdades da estrutura fundiária brasileira, a demanda por acesso à terra e as ameaças à posse da terra e de recursos naturais pelos diferentes grupos tradicionais justificam o Programa Novo Mundo Rural - Assentamento de Trabalhadores Rurais (MDA/GM e Incra). Deve-se ressalvar, no entanto, a evidente inconsistência do indicador previsto para esse programa, o que representa claro limite à sua gestão. Enquanto o programa anterior viabiliza o acesso à terra, o Programa Novo Mundo - Consolidação de Assentamentos (MDA/Incra e Banco da Terra) 
é componente central de uma política de desenvolvimento rural com base na agricultura familiar, já que disponibiliza a infra-estrutura social e produtiva para as novas unidades familiares de produção.

Outro ponto relevante trata dos avanços desproporcionais entre o número de famílias que tiveram a posse da terra garantida e aquelas que efetivamente têm condições de inserção competitiva no mercado, tornando necessário um conjunto de ações que representem a "porta de saída" das ações de ordenamento fundiário. Significa assegurar condições mínimas de vida (acesso aos serviços sociais básicos) e de produção para essas famílias, que tornam-se, assim, público do PRONAF. Para tanto, o PPA prevê um programa específico - Emancipação de Assentamentos Rurais (MDA/SDA e Incra) - podendo-se considerar, no entanto, que seus objetivos poderiam ser atingidos em caso de bom desempenho dos programas contidos no Novo Mundo Rural. Em caráter subsidiário e de suporte aos três programas finalísticos relativos à política fundiária, o PPA prevê o programa de Gestão de Política Fundiária (MDA/Incra), cujas ações voltam-se ao monitoramento, avaliação e qualificação das ações desenvolvidas naqueles.

Chega-se, assim, ao PRONAF, que objetiva alavancar a inserção econômica dos agricultores familiares. Recebe apoio do conjunto de informações dos Programas de Zoneamento Ecológico-econômico e Gerenciamento da Estrutura Fundiária e um afluxo de novos beneficiários por meio dos programas relativos à criação e estruturação de novas unidades produtivas. Como referido anteriormente, o PRONAF busca sintetizar uma "política subsetorial", na medida em que coordena diretamente ações relativas a componentes da política setorial preconizada pela Lei Agrícola. A análise de pertinência das ações desse programa será detalhada no item seguinte.

Os componentes necessários à política de desenvolvimento rural não contidos no PRONAF constam de seis outros programas. Esse conjunto de programas permite configurar, ao menos potencialmente, uma política de desenvolvimento rural com base na agricultura familiar. A garantia de preços mínimos e de condições estáveis de articulação entre a produção desses agricultores e o mercado pode ser provido por meio do Programa de Produção e Abastecimento Alimentar (MA/Conab e Ceagesp; MF). Por outro lado, deve-se prever ações de cobertura dos riscos de frustração de safra a que está sujeita a atividade agrícola em geral, pontos particularmente críticos para os agricultores familiares, em função da baixa qualidade dos solos de que normalmente dispõem e dos limites tecnológicos do setor. Isso é previsto, no PPA 2000-2003, pelo Programa de Seguro Rural (MA/GM, MF/Susep, Finatec), supondo-se que contenha instrumentos específicos e diferenciados para esse público e que seja operado em estreita articulação com o crédito do PRONAF. 
A consistência da política aqui delimitada requer que as ações específicas do PRONAF venham a ser complementadas por outras que garantam condições para uma efetiva melhoria das condições de produção e de vida das famílias. O PPA 2000-2003 apresenta programas que podem viabilizar melhorias na infra-estrutura, tanto produtiva como social, em caráter complementar à linha de Assistência Financeira a Projetos de Infraestrutura e Serviços Municipais do PRONAF. Em termos de infra-estrutura produtiva, há o Programa de Irrigação e Drenagem (MI/DNOCS, Codevasf, MF/BNB, Estados) dentro do qual destacam-se ações de construção e manutenção de infra-estrutura de irrigação de uso comum e de estudos para o aproveitamento do potencial produtivo de áreas irrigáveis. Igualmente relevante e diretamente associado ao apoio ao PRONAF, à assistência técnica e extensão rural, é o Programa de Conservação dos Solos na Agricultura (MA/Sarc e Embrapa; MDIC/BNDES) que tem por objetivo promover a recuperação do potencial produtivo de áreas agrícolas, tendo como ações mais relevantes à política delineada o financiamento da correção dos solos e a implantação de unidades demonstrativas.

Em termos de implantação de infra-estrutura social (que tende a ter impactos produtivos), há a perspectiva de que se preencham duas grandes lacunas existentes no meio rural. Uma é a energia elétrica, fator determinante da qualidade de vida no meio rural, que poderia ser suprida por meio do Programa Luz no Campo (companhias estaduais de eletricidade), voltado especificamente para o atendimento de áreas rurais. Estranha-nos o fato, no entanto, de que o programa encontra-se estruturado em ações estaduais, cobrindo apenas 17 unidades da Federação. A outra lacuna refere-se ao saneamento, contando-se, a princípio, com o Programa de Saneamento Básico (MS/Desan/Funasa, SIS/FNS), voltado para pequenos municípios (até 30.000 habitantes), o que permitiria o atendimento a pequenas localidades rurais, nada se podendo afirmar sobre a extensão às residências individuais dos agricultores.

Pode-se concluir pela existência de elementos, na seleção de programas do PPA 2000-2003, consistentes com o macroobjetivo de promover o desenvolvimento integrado do campo, focalizando a agricultura familiar. O somatório das ações ali contidas permite promover a geração de empregos e oportunidades de renda, contribuindo, assim, para o combate da pobreza e a promoção da cidadania e da inclusão social, conforme definido na orientação estratégica.

Se por um lado é possível identificar no PPA 2000-2003 um conjunto de programas que mostram relação de pertinência em relação à política preconizada, por outro, ao se analisar as ações ali contidas, constata-se o esvaziamento do potencial de integração e de contribuição dos mesmos. Isso ocorre porque os vários desenhos e recortes das ações pautam-se por critérios e parâmetros bastante distintos entre si e distantes da necessária 
diferenciação de ações, preconizada na $\mathrm{CF}$, visando atender o público composto pelos agricultores familiares. Daí decorrem evidentes dificuldades de articulação dos programas com o PRONAF, carro-chefe da atuação governamental voltada para o setor.

Reforça tais dificuldades a complexidade representada pela existência de vários ministérios, autarquias, fundações e empresas envolvidos nas ações, além dos Estados. Dada a inexistência de mecanismos de coordenação de ações intersetoriais no PPA 2000-2003, a atual estrutura programática torna praticamente inviável a implantação de uma política com as características aqui propostas. Há que se verificar se o Conselho Nacional de Desenvolvimento Rural Sustentável ou outra instância busca promover a articulação das várias iniciativas afins, o que certamente ampliaria as possibilidades de superação dessas dificuldades (vide representação da análise de pertinência no Anexo II).

\section{Análise da pertinência do PRONAF (vide Anexo III - Matriz lógica do PRONAF)}

Considera-se a existência de um programa voltado especificamente à implementação de ações de apoio à agricultura familiar não apenas pertinente, mas necessário, para uma política de desenvolvimento rural voltada à geração de empregos e renda. Tendo em vista as peculiaridades, a diversidade e as dificuldades de acesso desse setor às ações do poder público, o PRONAF é plenamente consistente com a orientação estratégica de combate da pobreza e promoção da cidadania e da inclusão social no meio rural, bem como com o macroobjetivo de promover o desenvolvimento integrado do campo, com foco na agricultura familiar.

As várias ações contidas no programa - financiamento de atividades de produção e agregação de valor, infra-estrutura, assistência técnica e extensão rural, qualificação profissional, apoio às organizações, pesquisa de tecnologias adaptadas - mostram-se também pertinentes em relação aos objetivos do programa. Como referido no item 3 , as dificuldades de acesso motivaram a opção pela reaplicação de ações já contidas em outros programas da política agrícola em geral, garantindo sua focalização, com algumas inovações. Há que se ponderar, no entanto, as possibilidades de efetiva articulação e complementaridade de tão amplo leque de ações, frente à complexidade de gestão existente - uma vez que o programa envolve nada menos que quatro ministérios e oito órgãos (MDA/GM e SDA; MF/STN, BB, BNB, Basa; MDIC/BNDES; MA/Sarc, Embrapa), além de Estados, empresas estaduais de extensão rural e municípios (vide Anexo IV — Unidades responsáveis).

Um problema decorrente da complexidade do programa é a existência de um indicador excessivamente genérico e pouco esclarecedor: 
taxa de atendimento das unidades familiares de produção (relação entre unidades atendidas com ações do programa e o total de unidades familiares existentes). Tal indicador não permite aferir o nível de execução das ações, pois estas prevêem produtos muito distintos, que não podem ser sintetizados nem convertidos no parâmetro acima descrito. Além disso, uma unidade pode ter sido atendida por assistência técnica, mas não por crédito. O principal limite do indicador, no entanto, decorre do fato de ele não permitir a mensuração do objetivo do programa, referente à melhoria na inserção comercial dos agricultores familiares. Para tanto, seria necessário proceder à combinação de outros indicadores, por exemplo, variações no nível médio de renda das famílias e no volume ou proporção de produção vendida anualmente por unidade produtiva.

Além disso, deve-se ressalvar que as denominações de algumas ações são pouco claras, deixando dúvidas quanto à real pertinência destas, face às indicações de sua sobreposição com outras ações, como:

- Desenvolvimento Rural x Assistência Financeira a Projetos de Infra-estrutura e Serviços Municipais;

- Concessão de Crédito para Implantação de Agroindústrias vinculadas à Agricultura Familiar x Desenvolvimento da Agroindústria de Agricultura Familiar.

\section{Análise da política quanto à sua suficiência}

\section{Análise da suficiência dos Programas Setoriais (vide Anexo I - Matriz lógica dos programas)}

O conjunto de programas setoriais apresenta-se, em uma primeira análise, suficiente para dar conta de uma política de desenvolvimento rural com base na agricultura familiar, desde que as demais políticas setoriais voltadas à produtividade e tecnologia agropecuária estejam disponíveis à população rural. Considerando-se os elementos previstos no arcabouço legal, em especial a Lei Agrícola, a maior parte dos elementos já é contemplada pelo próprio PRONAF, conforme analisado no item seguinte — inclusive os instrumentos fiscais de estímulo à atividade do setor, contemplados por meio dos subsídios previstos pela ação de crédito rural. Quanto aos demais elementos, os programas selecionados garantem "preços compatíveis com os custos de produção" e a comercialização dos produtos, o seguro agrícola, a eletrificação rural e a irrigação. Apenas um dos elementos previstos em lei, habitação rural, não foi devidamente contemplado na seleção de programas, nem se conseguiu constatar que constasse de outros programas do PPA 2000-2003. 
Por outro lado, dado o enfoque assumido para a política, identificou-se a necessidade de que fossem abordados outros temas, além dos previstos em lei. Dentre estes, alguns em caráter subsidiário à formulação e acompanhamento da política (Zoneamento Ecológico-econômico, Gerenciamento da Estrutura Fundiária, Gestão da Política Fundiária). Outros, referentes à garantia da posse da terra e de condições básicas de estruturação de novas unidades produtivas (assentamento, consolidação e emancipação de assentamentos rurais). Por fim, um programa voltado especificamente ao saneamento básico de pequenos municípios, supondose também extensível às localidades rurais.

Uma análise um pouco mais detida das ações que compõem cada um dos programas permitiu identificar os limites à suficiência destes para a política em questão. Os principais limites referem-se ao fato de que estes não consideraram a necessidade de atendimento diferenciado do público representado pelos agricultores familiares. Reveladora dessa limitação é a falta de padronização da terminologia utilizada pelos diferentes programas para caracterizar esse público: apesar da consagração acadêmica e política do termo agricultura familiar, persiste o uso de outras denominações, como "homem do campo", "produtor rural", "trabalhador rural".

No caso do Programa de Zoneamento Ecológico-econômico, a ausência de tratamento específico para esse setor expressa-se pelo recorte de ações por regiões, sendo muito provavelmente selecionadas sem considerar a concentração de agricultores familiares. O Programa de Gerenciamento da Estrutura Fundiária não dispõe de instrumentos referentes ao levantamento de informações sobre o universo das unidades familiares de produção, restringido-se às de maior porte. As ações dos Programas de Produção e Comercialização, de Seguro Rural, de Irrigação e Drenagem, por sua vez, não explicitam qualquer focalização no público em questão.

Deve-se considerar que cada programa atende a objetivos setoriais específicos, distintos e independentes de uma política que busque atender às necessidades do público dos agricultores familiares. Dados esses limites, pode-se concluir que dificilmente as ações PPA 2000-2003 serão suficientes para a efetivação da política de desenvolvimento rural considerada.

\section{Análise da suficiência do PRONAF (vide Anexo III - Matriz lógica do PRONAF)}

O PRONAF, ainda que contemplando vários dos elementos previstos na legislação referente à política agrícola, prioriza a melhoria da inserção econômica desses agricultores. Em função disso, tal programa, mesmo sendo o único voltado especificamente aos agricultores familiares, não é suficiente para que se alcance o "desenvolvimento integrado do campo" (Macroobejtivo 20), tido como multidimensional e não meramente econômico. 
Apesar de a Ação de Assistência Financeira a Projetos de Infraestrutura e Serviços nos Municípios abrir a possibilidade de superação de vários gargalos ao desenvolvimento rural, a eficácia da política dependerá, necessariamente, da complementaridade entre vários programas. Dentre eles os específicos (acesso à terra e às condições de produção, seguro agrícola, garantia de preços mínimos, acesso a insumos de qualidade, infraestrutura de irrigação etc.), até os de outros setores (educação, saúde, assistência social etc.).

Finalmente, há ainda um outro problema de suficiência, este intrínseco ao desenho da política. Considerando o público alvo do programa (4,1 milhões de agricultores familiares, ou de unidades familiares de produção, em 2000), há ações cujas metas para o período do PPA são extremamente limitadas, como:

- Capacitação, atingindo apenas 7\% do público;

- Concessão de Crédito para Incentivar a Produção Sem Uso de Agrotóxicos para apenas 200 agricultores;

- Desenvolvimento da Agroindústria de Agricultura Familiar, com apenas dez agroindústrias;

- Concessão de Crédito para Investimento para Agricultores Familiares para 4,4\% do público.

\section{Conclusão}

Pode-se constatar, a partir da análise aqui desenvolvida, que há um discurso governamental bem estruturado no que se refere ao desenvolvimento rural com base na agricultura familiar. Entretanto, quando se analisa a pertinência e a suficiência do planejamento, tendo por base esse discurso e o aparato legal existente, constatam-se vários limites. Por um lado, há limites relativos ao desenho de cada programa: indicadores inconsistentes, falta de padronização do recorte das ações e, em especial, da delimitação do público alvo. Por outro, há limites de ordem institucional, destacando-se a falta de instrumentos específicos para a coordenação e integração dos programas e ações, frente à multiplicidade dos órgãos por eles responsáveis. O PRONAF, apesar de buscar reunir várias ações referentes à política em questão, não contém todos os elementos necessários à política, nem pode contar com uma efetiva complementaridade com outros programas. Podese concluir, assim, que o PPA 2000-2003 não reflete a intenção expressa pelo discurso governamental nem expressa o planejamento consistente de uma política de desenvolvimento rural com base na agricultura familiar. 
Trabalho desenvolvido no âmbito da disciplina Políticas Públicas e Gestão por Programas do Curso de Formação para a Carreira de Especialista em Políticas Públicas e Gestão Governamental, coordenado pela ENAP Escola Nacional de Administração Pública.

\section{Referências bibliográficas}

Constituição da República Federativa do Brasil.

Decreto no 1.946, de 28 de junho de 1996.

Guanzirolli, C. E.; Cardin, S. C. S. (1999), "Agricultura Familiar no Brasil - Uma Análise a Partir do Censo Agropecuário de 95/96 - Versão Final.” Projeto de Cooperação Técnica Incra/FAO. Brasília.

Lei no 8.171, de 17 de janeiro de 1991.

Brasil. (s/d), Plano Plurianual 2000-2003. Secretaria de Planejamento e Investimentos Estratégicos do Ministério do Planejamento, Orçamento e Gestão. Brasília. 
Anexo I

Matriz lógica - seleção de programas relacionados ao desenvolvimento rural

\begin{tabular}{ll}
\hline Dimensão & Formulação (o discurso governamental) \\
\hline $\begin{array}{l}\text { Orientações } \\
\text { estratégicas }\end{array}$ & $\begin{array}{l}\text { Promover o desenvolvimento sustentável voltado para a geração } \\
\text { de empregos e oportunidades de renda. } \\
\text { Combater a pobreza e promover a cidadania e a inclusão social. }\end{array}$ \\
\hline Macroobjetivo & $\begin{array}{l}\text { Promover o desenvolvimento integrado do campo, com foco na } \\
\text { agricultura familiar. }\end{array}$ \\
\hline Agendas & $\begin{array}{l}\text { 1. Eixos Nacionais de Integração e Desenvolvimento; 2. Gestão } \\
\text { do Estado; 3. Ambiente; 4. Empregos e Oportunidades de Renda; }\end{array}$ \\
5. Informação e Conhecimento.
\end{tabular}

Programa: Zoneamento ecológico-econômico

Objetivos: Promover o zoneamento ecológico-econômico de regiões selecionadas, como forma de consolidar o processo de ocupação e de desenvolvimento de forma sustentável.

Problemas: Ocupação desordenada cria problema de sustentabilidade ecológica e econômica.

Indicador: Taxa de zoneamento ecológico-econômico.

Pressupostos/observações: Programa necessário para subsidiar políticas de desenvolvimento rural voltadas à agricultura familiar, mas com alcance limitado por estar restrito a áreas selecionadas onde pode não haver concentração desse público.

Programa: Gerenciamento da estrutura fundiária

Objetivos: Conhecer a efetiva distribuição, concentração, regime, uso e posse da terra. Problemas: Falta de informação sistematizada e confiável (não apenas declaratória) sobre a estrutura fundiária do país.

Indicador: Taxa de atualiz ação do Cadastro de Imóveis Rurais, Taxa Cadastramento de Área Rural.

Pressupostos/observações: Programa necessário para subsidiar políticas de desenvolvimento rural voltadas à agricultura familiar, mas com alcance limitado, pois restrito a informações sobre médios e grandes estabelecimentos.

Programa: Gestão da política fundiária

Objetivos: Apoiar o planejamento, avaliação e controle dos programas na área de política fundiária.

Problemas: Deficiência de acompanhamento dos programas voltados para a política fundiária.

Indicador:

Pressupostos/observações: Programa de Gestão de Políticas Públicas, que parece funcionar como um "guarda-chuva" para as ações do ministério. Pode viabilizar a articulação dos demais programas relacionados ao tema.

Programa: Novo mundo rural: assentamento de trabalhadores rurais

Objetivos: Assentar famílias de trabalhadores rurais, possibilitando o acesso do homem à terra.

Problemas: Falta de acesso à terra por famílias de trabalhadores rurais.

Indicador: Taxa de assentamento rural.

Pressupostos/observações: Ao viabilizar o acesso à terra por parte de trabalhadores rurais, cria condições para a estruturação inicial da produção agrícola familiar. Indicador precário e pouco confiável (fonte de informação sobre demandantes?). 
Programa: Novo mundo rural: consolidação de assentamentos

Objetivos: Prover os assentamentos de infra-estrutura social e de produção, de modo a garantir sua sustentabilidade para emancipação.

Problemas: Falta de infra-estrutura social e de produção nos assentamentos que inviabiliza a sustentabilidade.

Indicador: Taxa de integralização do atendimento às famílias assentadas.

Pressupostos/observações: Programa voltado à estruturação dos agricultores que acessariam a terra pelo programa anterior, "recebendo" o público daquele e "entregando-o" após a emancipação ao PRONAF, já como agricultores familiares com condições de inserção no mercado.

Programa: Emancipação de assentamentos rurais

Objetivos: Emancipar os assentamentos rurais criados até 1998, mediante atendimento complementar que lhes propiciem condições de sustentabilidade.

Problemas: Criação contínua de novos Projetos de Assentamentos, sem política para torná-los autônomos em relação ao poder público.

Indicador: Taxa de emancipação dos assentamentos rurais criados até 1998.

Pressupostos/observações: Projetos de assentamento, uma vez estruturados e emancipados - e, portanto, sustentáveis - darão origem a novos agricultores familiares, que passarão a ser atendidos pelo PRONAF e pelos demais programas voltados ao setor.

Programa: Agricultura familiar - PRONAF

Objetivos: Fortalecer a agricultura familiar, promovendo sua inserção competitiva nos mercados de produtos e fatores.

Problemas: Fraca inserção da agricultura familiar no mercado devido a dificuldades de acesso ao crédito, infra-estrutura e de capacitação.

Indicador: Taxa de atendimento de unidades familiares de produção.

Pressupostos/observações: Prevê ações existentes em outros programas, porém focalizadas no seu público, composto por agricultores estruturados e com inserção comercial. Supõe-se pleno acesso destes aos demais programas de política agrícola e outros setoriais (educação, saúde, assistência social, eliminação da pobreza, promoção da cidadania etc.).

Programa: Produção e abastecimento alimentar

Objetivos: Contribuir para a produção e o abastecimento de alimentos e atenuar oscilações de preços recebidos pelos produtores rurais.

Problemas: Irregularidade e/ou riscos no abastecimento alimentar da população urbana e instabilidade dos preços recebidos pelos produtores rurais.

Indicador: Previsão de safra e consumo aparente dos principais produtos básicos. Pressupostos/observações: Dadas as dificuldades na inserção comercial dos agricultores familiares e o perfil da sua produção, é um programa fundamental para a garantia da renda e a articulação com consumidores urbanos. Deve estar, portanto, diretamente vinculado às ações do PRONAF.

Programa: Seguro rural

Objetivos: Garantir compensação financeira aos agricultores em caso de frustrações de safras decorrentes da ação de agentes biológicos e climáticos.

Problemas: Atividade agrícola sujeita a perdas imprevistas causadas pelo clima ou por doenças, pragas etc.

Indicador: Taxa média de adesão ao seguro rural.

Pressupostos/observações: Agricultores familiares tendem a estar mais sujeitos aos riscos de frustração de safra (por limites tecnológicos e de qualidade dos solos). Supõe-se que contenha instrumentos específicos e diferenciados para esse público, associados ao créditos PRONAF. Dadas as dificuldades na inserção comercial dos agricultores familiares e o perfil da sua produção, é um programa fundamental para a garantia da renda e a articulação com consumidores urbanos. Deve estar, portanto, diretamente vinculado às ações do PRONAF. 
Programa: Conservação dos solos na agricultura

Objetivos: Recuperar áreas degradadas com vistas à sua reincorporação ao processo produtivo, mediante a adoção de práticas conservacionistas de uso e manejo adequados do solo e da água.

Problemas: Manejo inadequado resulta em degradação do solo e da água limitando o potencial produtivo.

Indicador: Área agrícola recuperada.

Pressupostos/observações: Agricultores familiares freqüentemente situam-se em solos pouco férteis, que tendem a ser degradados pelo manejo intensivo e/ou por tecnologia inadequada. Supõe-se que contenha instrumentos específicos e diferenciados para esse público.

\section{Programa: Irrigação e drenagem}

Objetivos: Promover o desenvolvimento sustentável de áreas irrigadas e irrigáveis, elevando os níveis de produção e produtividade agrícola e a melhoria das condições de vida do homem do campo.

Problemas: Falta de infra-estrutura em áreas com potencial para irrigação limita a produção, produtividade e melhoria das condições de vida das famílias.

Indicador: Produtividade agrícola das áreas irrigadas.

Pressupostos/observações: Programa complementar à política de desenvolvimento rural da agricultura familiar, viabilizando infra-estrutura complementar, mas não fica claro se há diferenciação para esse público. Indicador inconsistente (fórmula de cálculo não especificada), devendo ser substituído por outro (ex.: área total irrigada, taxa de área irrigada).

Programa: Luz do campo

Objetivos: Suprir de energia elétrica as áreas rurais não atendidas, contribuindo para a melhoria da qualidade de vida no campo.

Problemas: O baixo alcance da rede elétrica no meio rural diminui a qualidade de vida e o potencial produtivo.

Indicador:

Pressupostos/observações: Programa complementar à política de desenvolvimento rural da agricultura familiar, viabilizando infra-estrutura complementar. Embora não explicite focalização, objetivo indica prioridade para esse público.

Programa: Saneamento básico

Objetivos: Apoiar técnica e financeiramente as ações de saneamento a partir de critérios epidemiológicos para prevenção de controle de agravos, bem assim atender municípios com até 30.000 habitantes.

Problemas: Pequenos municípios com alta incidência de problemas de saúde por falta de saneamento básico.

Indicador: Taxa de abastecimento de água em municípios com menos de 30.000 habitantes. Pressupostos/observações: Programa complementar à política de desenvolvimento rural da agricultura familiar, viabilizando infra-estrutura complementar. Embora não explicite focalização, objetivo indica prioridade para esse público. 
Anexo II

Desenvolvimento rural com

base na agricultura familiar

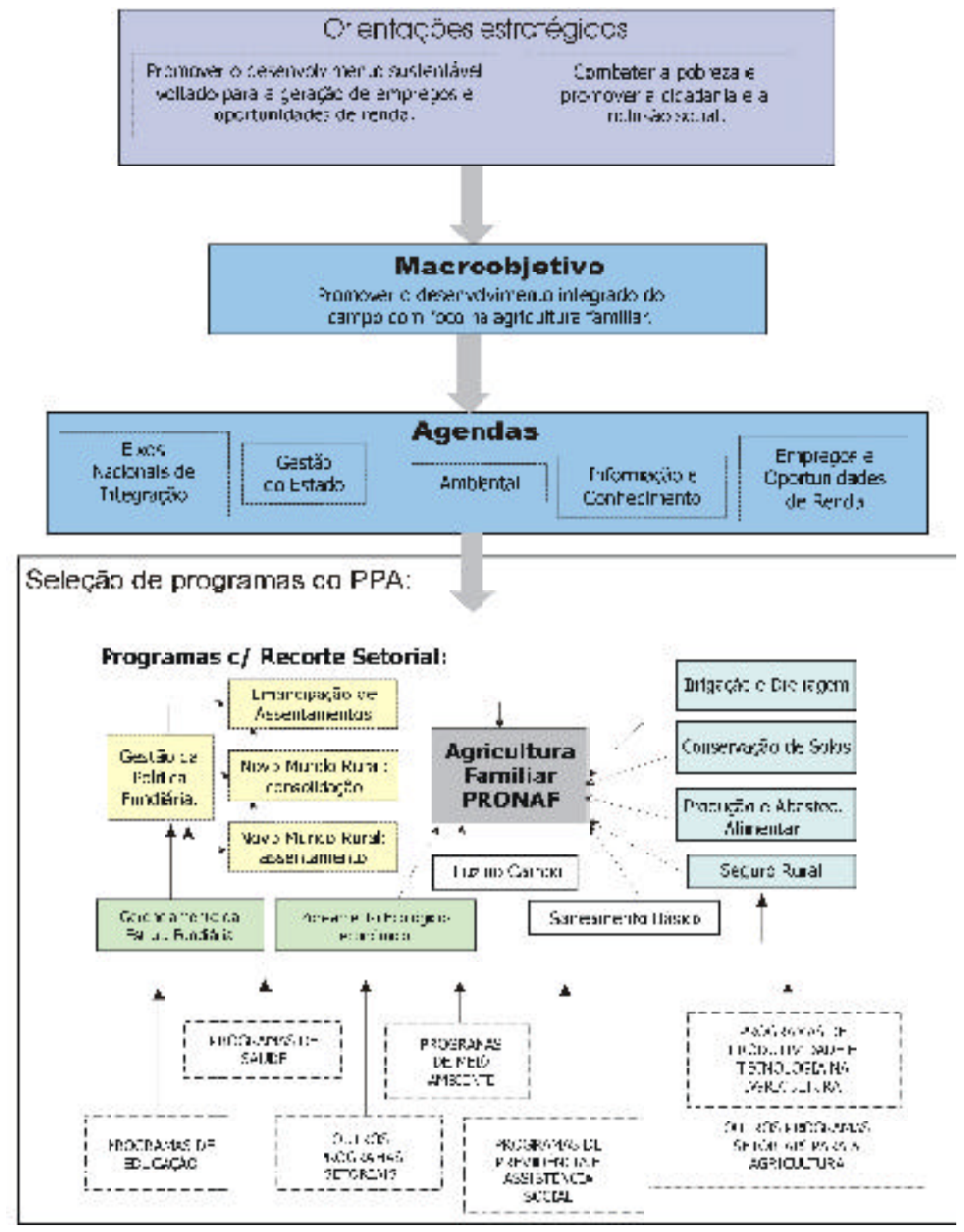


Elementos do programa: Agricultura familiar — PRONAF

Objetivos: Fortalecer a agricultura familiar, promovendo sua inserção competitiva nos mercados de produtos e fatores.

Problemas: Fraca inserção da agricultura familiar no mercado devido a dificuldades de acesso ao crédito, de infra-estrutura e de capacitação.

Indicador: Taxa de atendimento de unidades familiares de produção.

Pressupostos/observações: PRONAF focaliza dimensão produtiva/comercial. Outros programas deverão voltar-se à eliminação da pobreza, à promoção da cidadania e ao desenvolvimento integrado no campo (incluindo serviços de educação, saúde, assistência social etc.). Supõe-se também complementaridade com outros instrumentos de política agrícola (seguro, preços mínimos etc.).

Ações: Assistência financeira a projetos de infra-estrutura e serviços municipais Produtos: Municípios atendidos

Metas: 4.721

Pertinência das ações: Sim

Pressupostos/observações: Serviços sociais básicos e outras ações de infra-estrutura disponíveis. Incentiva estratégias municipais de desenvolvimento rural. Produtos da ação mal definidos.

Ações: Desenvolvimento rural

Produtos: Municípios apoiados

Metas: 18

Pertinência das ações: Ação indefinida

Pressupostos/observações: Não é possível avaliar.

Ações: Desenvolvimento do cooperativismo e associativismo rural

Produtos: Cooperativas assistidas

Metas: 9.510

Pertinência das ações: Sim

Pressupostos/observações: Existem iniciativas incipientes de organização a serem apoiadas. Meta coerente com os objetivos do programa.

Ações: Capacitação de agricultores familiares

Produtos: Agricultores capacitados

Metas: 291.081

Pertinência das ações: Sim

Pressupostos/observações: Meta insuficiente: apenas 7\% do público alvo do programa serão capacitados.

Ações: Execução da assistência técnica e extensão rural

Produtos: Produtores atendidos

Metas: 12.498 .296

Pertinência das ações: Sim

Pressupostos/observações: Há empresas aptas a prestar serviços de ATER. Meta coerente com os objetivos do programa.

Ações: Coordenação do sistema de assistência técnica e extensão rural

Produtos: Entidade coordenada

Metas: 108

Pertinência das ações: Sim

Pressupostos/observações: Há um sistema de ATER estruturado, apto a ser coordenado pelo programa. É tentativa de suprir as antigas funções desempenhadas pela EMBRATER. 


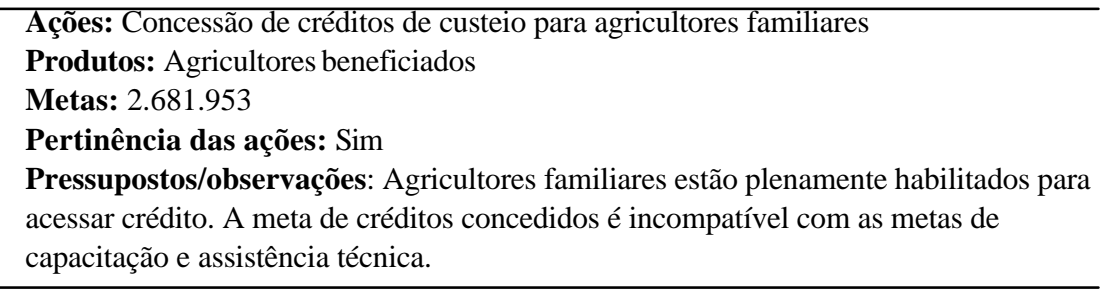

Ações: Concessão de créditos de investimento para agricultores familiares

Produtos: Agricultores beneficiados

Metas: 180.000

Pertinência das ações: Sim

Pressupostos/observações: Há AF aptos e habilitados para crédito; há ATER e seguro. Como alavancar agricultura familiar com apenas $4,4 \%$ dos agricultores financiados para investimento?

Ações: Concessão de créditos para implantação de agroindústrias vinculadas à AF Produtos: Agroindústria implantada

Metas: 5.000

Pertinência das ações: Sim

Pressupostos/observações: AF organizados, capacitados e estruturados para financiar projetos de AI. Meta insuficiente.

Ações: Concessão de crédito para incentivar a produção sem uso de agrotóxicos Produtos: Agricultores beneficiados

Metas: 200

Pertinência das ações: Sim

Pressupostos/observações: Há demanda por financiamento, tecnologia e sistemas de certificação. Meta insuficiente: valor apenas simbólico em relação ao público alvo potencial.

Ações: Financiamento e equalização de juros a AF

Produtos: -

Metas: 4

Pertinência das ações: Sim

Pressupostos/observações: Meta coerente com os objetivos do programa.

Ações: Remuneração às instituições financeiras públicas pelas operação de programa do governo.

Produtos: Projetos contratados

Metas: 4.580

Pertinência das ações: Sim

Pressupostos/observações: Meta inconsistente com as metas de crédito.

Ações: Desenvolvimento da agroindústria de agricultura familiar

Produtos: Agroindústria implantada

Metas: 10

Pertinência das ações: Ação indefinida

Pressupostos/observações: Meta insuficiente e sobreposta às metas de outras ações.

Ações: Pesquisas Tecnológicas para a AF

Produtos: Desenvolvimento tecnológico

Metas: 64

Pertinência das ações: Sim

Pressupostos/observações: Meta mal definida. 
Ações: Estudos de avaliação do desempenho do PRONAF

Produtos: Estudos realizados

Metas: 80

Pertinência das ações: Gestão do programa

Pressupostos/observações: Faltam informações para avaliar.

Ações: Monitoramento das ações de fortalecimento da agricultura familiar

Produtos: Ação monitorada

Metas: 8.900

Pertinência das ações: Gestão do programa

Pressupostos/observações: Estranha-nos o fato de o monitoramento ser realizado apenas no primeiro ano. 


\begin{tabular}{|c|c|}
\hline Programas/ações & Unidade responsável \\
\hline \multicolumn{2}{|l|}{ Programa de zoneamento ecológico-econômico } \\
\hline $\begin{array}{l}\text { Desenvolv. de metodol. p/ o zoneamento ecológico-econômico } \\
\text { nacional }\end{array}$ & MMA \\
\hline Estudos prospectivos de ordenamento territorial & MI \\
\hline Gestão integrada dos ambientes costeiros e marinhos & SQA/MMA \\
\hline Zoneamento ecológico-econômico da região nordeste & SUDENE/MI e Estados \\
\hline Zoneamento ecológico-econômico de áreas selecionadas & SUDENE/MI e Estados \\
\hline Zoneamento ecológico-econômico do Vale do São Francisco & SQA/MA \\
\hline Zoneamento ecológico-econômico na Amazônia Legal & MI e Estados \\
\hline Zoneamento ecológico-econômico no semi-árido nordestino & CODEVASF/MI \\
\hline Zoneamento econômico-ecológico do Distrito agropec. de Manaus & SUDAM/MI \\
\hline \multicolumn{2}{|l|}{ Programa de Gerenciamento da Estrutura Fundiária } \\
\hline Demarcação topográfica em ações de regularização fundiária & INCRA/MDA \\
\hline Georeferenciamento e levantamento do uso da terra & INCRA/MDA \\
\hline Gerenciamento do cadastro rural & INCRA/MDA \\
\hline Sistema de cadastro rural & INCRA/MDA \\
\hline \multicolumn{2}{|l|}{ Programa de gestão da política fundiária } \\
\hline Acompanhamento de conflitos e tensões sociais no campo & SDA/MDA \\
\hline $\begin{array}{l}\text { Cooperação Técnica p/ melhoria Gestão e Ações prod. em } \\
\text { áreas de assentamento }\end{array}$ & INCRA/MDA \\
\hline Estudos e pesquisas agrárias & MDA \\
\hline Promoção à qualidade e produtividade & INCRA/MDA \\
\hline \multicolumn{2}{|l|}{ Programa novo mundo rural: assentamento de trabalhadores rurais } \\
\hline Assistência jurídica às famílias acampadas & INCRA/MDA \\
\hline Concessão de crédito p/ aquisição de imóveis rurais — Banco da Terra & INCRA/MDA \\
\hline Concessão de crédito-instalação de famílias assentadas & GM/MDA \\
\hline Discriminação de áreas devolutas e terras irregularm. ocupadas & INCRA/MDA \\
\hline Identificação de imóveis passíveis de desapropriação e aquisição & INCRA/MDA \\
\hline Obtenção de terras & INCRA/MDA \\
\hline Perícia judicial em ações de desapropriação de imóveis & INCRA/MDA \\
\hline Plano de desenvolvimento do assentamento rural & INCRA/MDA \\
\hline Reassentamento de "não índios" ocupantes de terras indígenas & INCRA/MDA \\
\hline Sistema de Informações de Projetos de Reforma Agrária (SIPRA) & INCRA/MDA \\
\hline Titulação de terras & INCRA/MDA \\
\hline Topografia em áreas de assentamento rural & INCRA/MDA \\
\hline \multicolumn{2}{|l|}{ Programa novo mundo rural: consolidação de assentamentos } \\
\hline Acompanhamento da instalação de projetos de assentamentos rurais & INCRA/MDA \\
\hline Administração e operação do complexo industrial — PACAL & INCRA/MDA \\
\hline
\end{tabular}




\begin{tabular}{|c|c|}
\hline Assistência técnica e capacitação de assentados — LUMIAR/PRONERA & INCRA/MDA \\
\hline $\begin{array}{l}\text { Concessão crédito p/ implantação de infra-estrututura básica - } \\
\text { Banco da Terra }\end{array}$ & $\begin{array}{l}\text { Banco da } \\
\text { Terra/MDA }\end{array}$ \\
\hline $\begin{array}{l}\text { Concessão crédito p/ implantação infra-estrutura básica - } \\
\text { Cédula da terra }\end{array}$ & INCRA/MDA \\
\hline Investimento em infra-estrutura básica para assentamentos rurais & INCRA/MDA \\
\hline $\begin{array}{l}\text { Programa de emancipação de assentamentos rurais assist. } \\
\text { técn. e capacit. famílias assent. em proj. até } 1998 \text { - LUMIAR }\end{array}$ & INCRA/MDA \\
\hline Capacitação de agentes culturais nas áreas de reforma agrária & SDAMDA \\
\hline $\begin{array}{l}\text { Concessão de crédito-instalação das famílias assent. } \\
\text { proj. até } 1998\end{array}$ & INCRA/MDA \\
\hline Infra-estrutura complem. p/ emancipação de assentam. até 1998 & INCRA/MDA \\
\hline Plano de desenvolvim ento dos assentamentos rurais criados at é 1998 & INCRA/MDA \\
\hline Topografia em áreas de assentamentos rurais criados até 1998 & INCRA/MDA \\
\hline \multicolumn{2}{|l|}{ Programa de Agricultura Familiar (PRONAF) } \\
\hline Assistência financ. a projetos de infra-estrut. e serviços municipais & GM/MDA \\
\hline 49.3651 - Capacitação de agricultores familiares & GM/MDA \\
\hline Concessão de crédito para agricultores familiares & $\begin{array}{l}\text { BNB/MF.BB/MF } \\
\text { e BASA/MF }\end{array}$ \\
\hline $\begin{array}{l}\text { Concessão de crédito para implantação de agroindústrias } \\
\text { vinculadas à agricultura familiar }\end{array}$ & BNDES/MDIC \\
\hline Concessão de crédito $\mathrm{p} /$ incentivar a prod. sem uso de agrotóxicos & BNDES/MDIC \\
\hline Coordenação do sistema de assistência técnica e extensão rural & SDA/MDA \\
\hline Desenvolvimento da agroindústria de agricultura familiar & SARC/MA \\
\hline Desenvolvimento do cooperativismo e associativismo rural & SDA/MDA \\
\hline Desenvolvimento rural & SARC/MA \\
\hline Estudos de avaliação do desempenho do PRONAF & SDA/MDA \\
\hline Execução da assistência técnica e extensão rural & GM/MDA \\
\hline $\begin{array}{l}\text { Financiamento e equalização de juros para a } \\
\text { agricultura familiar }\end{array}$ & $\begin{array}{l}\text { SARC/MAe } \\
\text { entidades estaduais } \\
\text { de extensão rural }\end{array}$ \\
\hline Monitoramento das ações de fortalec. da agricultura familiar & STN/MF \\
\hline Pesquisas tecnológicas para a agricultura familiar & SDA/MDA \\
\hline $\begin{array}{l}\text { Remun. às instit. financ. públicas - operac. programa } \\
\text { de governo - PRONAF }\end{array}$ & EMBRAPA/MA \\
\hline \multicolumn{2}{|l|}{ Programa de produção e abastecimento alimentar } \\
\hline Administração da rede armazenadora & CONAB/MA \\
\hline Aquisição de produtos de alimentação básica & CONAB/MA \\
\hline $\begin{array}{l}\text { Equalização de juros e de outros encargos financ. em oper. de } \\
\text { invest. rural e agroind. (lei no } 8.427 / 92 \text { ) }\end{array}$ & MF \\
\hline $\begin{array}{l}\text { Financiamento e equal. de juros em oper. de empréstimos do governo } \\
\text { federal EGF (lei no } 8.427 / 92 \text { ) }\end{array}$ & MF \\
\hline $\begin{array}{l}\text { Financiamento e equalização de juros nas operações de } \\
\text { custeio agropecuário (lei no } 8.427 / 92 \text { ) }\end{array}$ & MF \\
\hline $\begin{array}{l}\text { Financiamento e equal. de preços nas aquisições do governo } \\
\text { federal e na form. de estoques regul. e estrat. AGF (lei no 8.427/92) }\end{array}$ & MF \\
\hline
\end{tabular}




\begin{tabular}{|c|c|}
\hline Fiscalização de estoques públicos de alimentos & CONAB/MA \\
\hline Formação de estoques públicos - AGF/BB/CONAB & CONAB/MA \\
\hline $\begin{array}{l}\text { Garantia e sustentação de preços na comerc. de prod. } \\
\text { agropec. (MP no } 1.886-39 / 99 \text { ) }\end{array}$ & MF \\
\hline Manutenção da infra-estrutura operacional & CEAGESP/MA \\
\hline $\begin{array}{l}\text { Operacionalização da comercialização de produtos de } \\
\text { alimentação básica }\end{array}$ & CONAB/MA \\
\hline \multicolumn{2}{|l|}{ Programa de seguro rural } \\
\hline Julgamento de recursos em processos de sinistros & GM/MA \\
\hline Manutenção da estabilidade dos prêmios do seguro rural & SUSEP/MF \\
\hline Zoneamento agroclimático & $\begin{array}{l}\text { GM/MA, } \\
\text { FINATEC }\end{array}$ \\
\hline Zoneamento pedoclimático & $\begin{array}{l}\text { GM/MA, } \\
\text { FINATEC }\end{array}$ \\
\hline \multicolumn{2}{|l|}{ Programa de conservação de solos na agricultura } \\
\hline Conservação e correção de solos & MA \\
\hline $\begin{array}{l}\text { Conservação e preservação dos solos agricultáveis } \\
\text { no Estado de São Paulo }\end{array}$ & MA \\
\hline Correção, conservação e preservação de solos na agricultura & EMBRAPA/MA \\
\hline Financiamento ao uso de corretivos de solo (Pró-solo) & BNDES/MDIC \\
\hline $\begin{array}{l}\text { Implantação de unidades demonstr. de manejo e } \\
\text { conservação de solo e de água }\end{array}$ & SARC/MA \\
\hline $\begin{array}{l}\text { Pesquisa e desenvolvimento em manejo e conservação de } \\
\text { solo e água }\end{array}$ & EMBRAPA/MA \\
\hline \multicolumn{2}{|l|}{ Irrigação e drenagem } \\
\hline $\begin{array}{l}\text { Construção de obras de infra-estrutura de irrigação de uso } \\
\text { comum: demais }\end{array}$ & MI \\
\hline Emancipação de perímetros de irrigação & $\begin{array}{l}\text { DNOCS/MI, } \\
\text { CODEVASF/MI, } \\
\text { MI }\end{array}$ \\
\hline Estudo de suporte técnico operacional & MI \\
\hline Estudos para o aproveitamento hidroagrícola em áreas irrigáveis & CODEVASF/MI \\
\hline Financiamento de projetos do novo modelo de irrigação & $\mathrm{BNB} / \mathrm{MF}$ \\
\hline Manutenção da infra-estrutura de irrigação de uso comum & $\begin{array}{l}\text { CODEVASF/ } \\
\text { MI/DNOCS/MI, } \\
\text { MI e Estados }\end{array}$ \\
\hline Promoção de oportunidades de investimentos & Codevasf/MI \\
\hline \multicolumn{2}{|l|}{ Programa luz no campo } \\
\hline $\begin{array}{l}\text { Implantação de rede rural de distribuição de energia } \\
\text { elétrica em Goiás }(14.223 \mathrm{~km})\end{array}$ & $\begin{array}{l}\text { CELG } 1 \text { e } \\
\text { CELG } 2\end{array}$ \\
\hline $\begin{array}{l}\text { Implantação de rede rural de distribuição de energia elétrica } \\
\text { em Mato Grosso do Sul }(3.081 \mathrm{~km})\end{array}$ & ENERSUL \\
\hline $\begin{array}{l}\text { Implantação de rede rural de distribuição de energia elétrica em } \\
\text { Minas Gerais }(25.501 \mathrm{~km})\end{array}$ & $\begin{array}{l}\text { CEMIG1 } \\
\text { CEMIG } 2 \text { e CFLCL }\end{array}$ \\
\hline $\begin{array}{l}\text { Implantação de rede rural de distribuição de energia elétrica na } \\
\text { Paraíba }(2.548 \mathrm{~km})\end{array}$ & $\begin{array}{l}\text { CELB e } \\
\text { SAELPA }\end{array}$ \\
\hline $\begin{array}{l}\text { Implantação de rede rural de distribuição de energia } \\
\text { elétrica em Pernambuco }(22.684 \mathrm{~km})\end{array}$ & $\begin{array}{l}\text { CELPE } 1 \text { e } \\
\text { CELPE } 2\end{array}$ \\
\hline
\end{tabular}




\begin{tabular}{|c|c|}
\hline $\begin{array}{l}\text { Implantação de rede rural de distribuição de energia } \\
\text { elétrica em Roraima }(3.230 \mathrm{~km})\end{array}$ & CER \\
\hline $\begin{array}{l}\text { Implantação de rede rural de distribuição de energia } \\
\text { elétrica em Santa Catarina }(3.840 \mathrm{~km})\end{array}$ & CELESC \\
\hline $\begin{array}{l}\text { Implantação de rede rural de distribuição de energia } \\
\text { elétrica em São Paulo }(5.317 \mathrm{~km})\end{array}$ & $\begin{array}{l}\text { CSPE, ELEKTRO, } \\
\text { EEVP, EEB, EBE, } \\
\text { CPFL, CNEE, } \\
\text { CLFSC e Caiuá }\end{array}$ \\
\hline $\begin{array}{l}\text { Implantação de rede rural de distribuição de energia } \\
\text { elétrica em Sergipe }(5.952 \mathrm{~km})\end{array}$ & $\begin{array}{l}\text { ENERGIPE e } \\
\text { SULGIPE }\end{array}$ \\
\hline $\begin{array}{l}\text { Implantação de rede rural de distribuição de energia } \\
\text { elétrica na Bahia }(16.855 \mathrm{~km})\end{array}$ & COELBA \\
\hline $\begin{array}{l}\text { Implantação de rede rural de distribuição de energia } \\
\text { elétrica no Ceará }(6.733 \mathrm{~km})\end{array}$ & COELCE \\
\hline $\begin{array}{l}\text { Implantação de rede rural de distribuição de energia } \\
\text { elétrica no Distrito Federal }(575 \mathrm{~km})\end{array}$ & CEB \\
\hline $\begin{array}{l}\text { Implantação de rede rural de distribuição de energia } \\
\text { elétrica no Mato Grosso }(23.716 \mathrm{~km})\end{array}$ & CEMAT \\
\hline $\begin{array}{l}\text { Implantação de rede rural de distribuição de energia } \\
\text { elétrica no Paraná }(7.741 \mathrm{~km})\end{array}$ & $\begin{array}{l}\text { CFLO, COCEL } \\
\text { e COPEL }\end{array}$ \\
\hline $\begin{array}{l}\text { Implantação de rede rural de distribuição de energia } \\
\text { elétrica no Rio de Janeiro }(5.570 \mathrm{~km})\end{array}$ & $\begin{array}{l}\text { LIGHT, CERJ1, CERJ2 } \\
\text { e CENF. }\end{array}$ \\
\hline $\begin{array}{l}\text { Implantação de rede rural de distribuição de energia } \\
\text { elétrica no Rio Grande do Sul (17.415 km) }\end{array}$ & $\begin{array}{l}\text { RGE, AESUL } \\
\text { e CEEE }\end{array}$ \\
\hline $\begin{array}{l}\text { Implantação de rede rural de distribuição de energia } \\
\text { elétrica no tocantins }(36.667 \mathrm{~km})\end{array}$ & CELTINS \\
\hline \multicolumn{2}{|l|}{ Programa de saneamento básico } \\
\hline Ações de saneamento básico em pequenas localidades & $\begin{array}{l}\text { DESAN/ } \\
\text { FUNASA/MS }\end{array}$ \\
\hline $\begin{array}{l}\text { Construção e ampliação ou melhoria de sistema de coleta } \\
\text { e tratamento de esgoto sanitário para controle de agravos }\end{array}$ & $\begin{array}{l}\text { DESAN/ } \\
\text { FUNASA/MS }\end{array}$ \\
\hline $\begin{array}{l}\text { Construção e ampliação ou melhoria dos serviços de } \\
\text { abastecimento de água para controle de agravos }\end{array}$ & $\begin{array}{l}\text { DESAN/ } \\
\text { FUNASA/MS }\end{array}$ \\
\hline $\begin{array}{l}\text { Implantação de melhorias sanitárias domiciliares p/ } \\
\text { controle de agravos }\end{array}$ & $\begin{array}{l}\text { DESAN/ } \\
\text { FUNASA/MS }\end{array}$ \\
\hline $\begin{array}{l}\text { Implantação dos serviços de abastecim. água — saúde e } \\
\text { saneam. no Piauí }\end{array}$ & SIS/FNS/MS \\
\hline $\begin{array}{l}\text { Implant. dos sistemas de esgotam. sanitário — saúde e } \\
\text { saneam. no Piauí }\end{array}$ & SIS/FNS/MS \\
\hline $\begin{array}{l}\text { Implantação e ampliação ou melhoria de sistemas de } \\
\text { coleta, tratamento e destinação final de resíduos sólidos para } \\
\text { controle de agravos }\end{array}$ & $\begin{array}{l}\text { DESAM/ } \\
\text { FUNASA/MS }\end{array}$ \\
\hline
\end{tabular}


Elementos para uma política de desenvolvimento rural com base na agricultura familiar — a inserção do PRONAF no PPA 2000-2003

Alexandre Pires Domingues, Aloisio Lopes Pereira de Melo, Antonio Dias de

Hollanda e Renato Alves Morato

Revista do

Serviço

Público

Este artigo analisa em que medida o Plano Plurianual — PPA 2000-2003 reflete a existência de uma política nacional de desenvolvimento rural com base na agricultura familiar. A partir da delimitação dos elementos necessários para tal política, procede-se à identificação dos programas no PPA que, em princípio, contemplam tais elementos. Analisa-se a seguir as relações lógicas de pertinência e de suficiência de tais programas e, mais detidamente, do Programa Nacional de Fortalecimento da Agricultura Familiar (PRONAF). Constata-se que tal política somente poderia se concretizar mediante uma estreita articulação entre este e diversos outros programas. Esse fator, somado à complexidade do PRONAF — que contém uma grande diversidade de ações, inclusive de caráter multissetorial (executadas por outros órgãos e entidades) indica a dificuldade para a efetivação da política preconizada pelo discurso governamental. Este trabalho foi desenvolvido no âmbito da disciplina "Políticas Públicas e Gestão por Programas" do Curso de Formação para a Carreira de Especialista em Políticas Públicas e Gestão Governamental, coordenado pela ENAP Escola Nacional de Administração Pública.

\section{Elementos para una política de desarollo rural basada en la agricultura familiar - la inserción del PRONAF en el PPA 2000-2003 \\ Alexandre Pires Domingues, Aloisio Lopes Pereira de Melo, Antonio Dias de Hollanda y Renato Alves Morato}

Este artículo analisa en que medida el Plan Plurianual Brasileño - PPA refleja la existencia de una política nacional de desarollo rural con base en la agricultura familiar. A partir de la delimitación de los elementos necesários para tal política, se procede a la identificación de los programas en el PPA que, en principio, contemplan eses elementos. Se analisan, a seguir, las relaciones lógicas de pertinencia y de suficiencia de eses Programas y, más detenidamente, del PRONAF — Programa Nacional de Fortalecimiento de la Agricultura Familiar. Se comprueba que tal política solamente podría concretizarse mediante una estrecha articulación entre este y otros diversos programas. Ese factor, sumado a la complejidad del PRONAF — que contiene una gran diversidad de acciones, incluso de caracter multi-sectorial (ejecutadas por otras instituciones y entidades) indica la dificuldade para la efetivación de la política expresada por el discurso gubernamental. Ese trabajo fué desenvuelto en el ámbito de la disciplina "Políticas Públicas y Gestión por Programas" del Curso de Formación para la Carrera de Especialista en Políticas Públicas y Gestión Gubernamental, cordinado por la ENAP Escuela Nacional de Administración Pública.

\section{Components of a rural development policy based on family farming - the insertion of PRONAF in the PPA 200-2003 \\ Alexandre Pires Domingues, Aloisio Lopes Pereira de Melo, Antonio Dias de Hollanda and Renato Alves Morato}

This article analyses to which extension the Brazilian government mid-term Plan (Plano Plurianual - PPA 2000-2003) contains a policy for rural development based on family farming. It starts stablishing the components of such policy. Then, the authors proceed to a selection of programs of PPA 2000-2003 in which such components should be

Especialistas em Políticas Públicas e Gestão Governamental. 
contained. Then, an analysis of the logical relationships of concernment and sufficiency between such programs is made, with special attention to the National Program of Family Farming Strenghtening (PRONAF). It is stated that this policy could only become effective if there was a close integration between PRONAF and other programs. This statement and the high complexity of PRONAF — which contains a great variety of actions, including those inter-sectorial (operated by different ministries and other federal organizations) indicate that the policy expressed by government speech would hardly become effective. This article was originally written for the discipline of "Public Policies and Public Management by Programs", as part of the Training Course for the Career of Public Policies and Government Management Specialist of the Brazilian Federal Government, coordinated by ENAP National School of Public Management. 